\title{
Synthesis of High-performance Composites of Poly(4-vinylpyridine-co-styrene) Copolymer (P4VPy-St) and Polyimides (PI) Having Carboxyl Pendant Groups by in-situ Polymerization and Their Mechanical Properties
}

\author{
Ryo Hamada, Keiichi Kaneko, Yuko TAKeoka, Masahiro Rikukawa, and Kohei SAnui ${ }^{\dagger}$ \\ Department of Chemistry, Sophia University, 7-1 Kioi-cho, Chiyoda-ku, Tokyo 102-8554, Japan
}

(Received April 16, 2004; Accepted June 23, 2004; Published October 15, 2004)

\begin{abstract}
High-performance composites of poly(4-vinylpyridine-co-styrene) copolymer (P4VPy-St) and polyamic acids (PAA) were prepared by in-situ polymerization. High-performance composites could be obtained from a polymer pair that has an attractive interaction such as a hydrogen bonding interaction. The aggregation of the resulting polyimide (PI) took place easily in the P4VPy-St/PI composite film during the stepwise heat-treatment of the P4VPySt/PAA composite film to convert PAA to PI. This was because of the disappearance of the carboxyl group due to the imidization of PAA. In this study, free carboxylic acid groups were introduced into the side chains of PI in order to improve the mechanical properties of P4Py-St/PI composites, and the carboxyl group content dependence of the tensile strength of the resulting composite films was investigated. The tensile strength of the resulting composite films increased with increasing carboxyl group content in PI. The hydrogen bonding interaction between the pyridine moiety in the $\mathrm{P} 4 \mathrm{VPy}-\mathrm{St}$ copolymer and the carboxyl group introduced into PI greatly enhanced both the compatibility and the tensile strength of the composite films. [DOI 10.1295/polymj.36.824]

KEY WORDS in-situ Polymerization / High-performance Composites / Hydrogen Bonding Interaction / Compatibility / Mechanical Properties / Tensile Strength / Blend /
\end{abstract}

Many polymer composites reinforced by high-performance fibers such as carbon, glass, or aramide fibers have been developed in the field of engineering materials. Important factors that influence the properties of the resulting composites are the interactions between the reinforcing polymers and the matrix polymers. Moreover, it is expected that a fine dispersion of the reinforcing polymer would result in a higher reinforcing effect. Some studies have been conducted in order to obtain molecular-level polymer composites, so called molecular composites, which have been proposed by Takayanagi et al. and by Hang et al. ${ }^{1-3} \mathrm{In}$ general, the compatibility of the rigid rod polymers that are used as reinforcing materials with the flexible polymers used as matrices is usually so poor that blending of these two polymers is very difficult, either in the melt state or in a solution. Therefore, 'in-situ polymerization' has been introduced in high-performance composite preparation. ${ }^{4-7}$ For example, microcomposites of poly( $\gamma$-methyl-L-glutamate) (PMLG) and SBR derivatives were prepared by both a blending method and the in-situ polymerization method, where polymerization of $\gamma$-methyl-L-glutamate NCA was carried out in a solution of SBR derivatives with $n$ hexylamine as an initiator. We have already reported that there were great differences in mechanical properties and morphology between the composites prepared by a blending method and those prepared by in-situ polymerization. ${ }^{8}$ The tensile strength and modulus of the films obtained by the in-situ polymerization method increased with increasing PMLG content.

Our attention has been focused on pairs of polymers that have attractive interactions such as hydrogen bonding interaction and charge-transfer interaction. It was reported that, as a result of hydrogen bond formation, such polymers are compatible. They show single $T_{\mathrm{g}}$ values appreciably higher than those of either of the individual components of the mixture because of the formation of hydrogen-bonded complexes. ${ }^{9}$ Hydrogen bonds have also been used for the preparation of compatible blends, such as liquidcrystalline polymer blends formed from a thermotropic polyester containing a lateral pyridyl group and poly(4-vinylphenol). ${ }^{10}$ In addition, Kato et al. reported that a liquid-crystalline phase and polymer network could be constructed by molecular self-assembly through noncovalent interactions such as intermolecular hydrogen bonding between a polyacrylate containing a benzoic acid moiety (H-bond donor) as a sidechain and the pyridine derivatives as H-bond acceptors. ${ }^{11}$

Previously, we have reported that the hydrogen bonding interaction between the pyridine moiety in matrix P4VPy-St copolymer and the resulting polyamic acid (PAA) enhanced both the miscibility and mechanical properties of the composites. Furthermore,

${ }^{\dagger}$ To whom correspondence should be addressed (E-mail: k-sanui@sophia.ac.jp). 
a polyimide (PI) structure was formed by stepwise heat-treatment and this greatly enhanced the tensile strength of the composite films. ${ }^{12}$ In this work, we have carried out the introduction of carboxyl groups into pendant groups of PAA or PI in order to improve the mechanical properties of $\mathrm{P} 4 \mathrm{VPy}-\mathrm{St} / \mathrm{PAA}$ or PI composites.

This paper describes the preparation of composites of P4VPy-St/PAA or PI having carboxyl pendant groups and the effect of carboxyl group content on the tensile strength of the resulting composite films.

\section{EXPERIMENTAL}

\section{Reagents and Solvents}

Commercially available reagents and monomers of special grade were purified by conventional methods. All solvents were purified by distillation prior to use. $\mathrm{P} 4 \mathrm{VPy}-\mathrm{St}(4 \mathrm{VPy} / \mathrm{St}=5 / 5)$ was prepared according to the procedure previously reported by a radical copolymerization of styrene (St) and 4-vinylpyridine (4-VPy) using 2,2'-azobis(isobutyronitrile) (AIBN) as an initiator. ${ }^{13,14}$

\section{In-situ Polymerization Method}

A typical in-situ polymerization of pyromellitic dianhydride (PMDA) and various molar ratios of $m$ phenylene diamine (MPDA)/3,5-diamino-bennzoic acid (DABA) was carried out at room temperature in $N, N$-dimethyl-acetamide (DMAc) solutions of P4VPy-St in the monomer concentration of 0.25 $\mathrm{mol} / \mathrm{L}$ as follows: P4VPy-St $(1.15 \mathrm{~g})$ was first dissolved in DMAc $(21.7 \mathrm{~mL})$ and then MPDA $(0.292 \mathrm{~g}$, $2.70 \mathrm{mmol})$ and DABA $(0.411 \mathrm{~g}, 2.70 \mathrm{mmol})$ were dissolved in the solution. Then PMDA $(0.118 \mathrm{~g}, 5.40$ mmol) was added into the solution at room temperature with stirring under nitrogen atmosphere. After $24 \mathrm{~h}$ a yellowish viscous solution was obtained. The solution was cast on a glass plate and the solvent was evaporated in vacuum. Obtained films were washed with methanol repeatedly, followed by drying under reduced pressure. Imidization of poly(amic acid) (PAA) was carried out under the following conditions: $1 \mathrm{~h}$ at $120^{\circ} \mathrm{C}, 1 \mathrm{~h}$ at $180^{\circ} \mathrm{C}, 2 \mathrm{~h}$ at $220^{\circ} \mathrm{C}$ in vacuum as shown in Scheme 1. Various composites of P4VPy-St $(4 \mathrm{VPy} / \mathrm{St}=5 / 5)$ and polyimides having different contents of carboxyl pendant groups were prepared according to a procedure similar to that described above.

\section{Solution Blend Method}

The conventional polymerization of a given molar ratio of MPDA/DABA with PMDA was carried out in DMAc to obtain PAA having various contents of carboxyl groups as follows: A given molar ratio of MPDA/DABA was dissolved in DMAc; then PMDA was added into the solution with stirring at room temperature for $24 \mathrm{~h}$ under nitrogen atmosphere. After 24 $\mathrm{h}$ a yellowish viscous solution was obtained. The solution was then poured into excess pure water to precipitate the resulting polymer. The precipitate was collected by filtration and then dried under reduced pressure at $45^{\circ} \mathrm{C}$ for $24 \mathrm{~h}$. The results of syntheses of PAAs are shown in Table I.

A $20 \mathrm{wt} \%$ DMAc solution of PAA was mixed slowly with a $20 \mathrm{wt} \%$ DMAc solution of P4VPy-St copolymer. The stirring was continued at $40{ }^{\circ} \mathrm{C}$ for $24 \mathrm{~h}$. Then, the solution was directly used for casting onto a glass plate to form a film. The resulting film was dried at $80^{\circ} \mathrm{C}$ for $12 \mathrm{~h}$, then under reduced pressure for $24 \mathrm{~h}$. Composites were prepared by this blend method in several ratios of PAA to the P4VPy-St copolymers.

\section{Characterization of Polymers and the Composite Films}

Gel permeation chromatography (GPC) measurements of the P4VPy-St copolymer were performed with a Shimadzu Class-VP System. Two gel columns, Shodex KD804 and KD805, were used with DMF as the eluent at $50^{\circ} \mathrm{C}$.

Identification, thermal properties, mechanical properties, and morphology of the films obtained by the insitu polymerization method and the blend method were investigated.

Thermal properties were evaluated by thermogravimetric and differential thermal analysis (Seiko TGDTA 200).

The morphology of the film surface fractured in liquid nitrogen was observed by scanning electron microscopy (SEM, Hitachi S-4500).

Mechanical properties were measured by using a tensile testing machine (Shimadzu Autograph AGS$1 \mathrm{kNA}$ ) at room temperature at the cross speed of $2 \mathrm{~mm} / \mathrm{min}$ for all samples.

Polymers and composites were identified by elemental analysis and FT-IR.

\section{RESULTS AND DISCUSSION}

Synthesis of P4VPy-St Copolymer and PAAs having Various Contents of Carboxyl Groups

The P4VPy-St having a copolymer composition of $4-\mathrm{VPy} / \mathrm{St}=5 / 5$ molar ratios was synthesized by a conventional radical copolymerization of St and 4VPy, using AIBN as an initiator. The copolymer composition of P4VPy-St (5/5) obtained was confirmed by elemental analyses and ${ }^{1} \mathrm{H}$ NMR measurements. The P4VPy-St (5/5) copolymer has $M_{\mathrm{n}}=159,000$, $M_{\mathrm{w}}=441,000, M_{\mathrm{w}} / M_{\mathrm{n}}=2.77$; these values were estimated by GPC (Shimadzu Class-VP) in DMF based 
(a)

m<smiles>C=Cc1ccncc1</smiles>

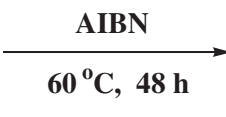<smiles>CCCCCC(CC)c1ccncc1</smiles>

(b)

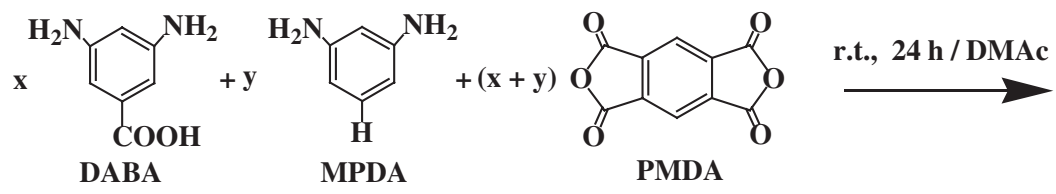

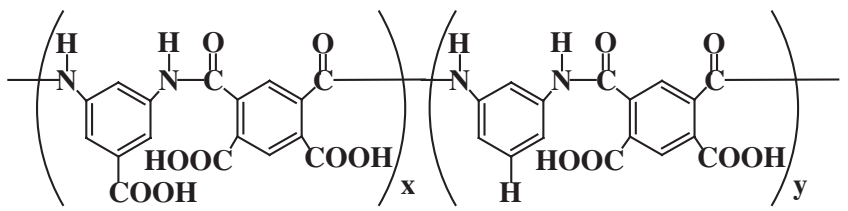

PAA

(c)

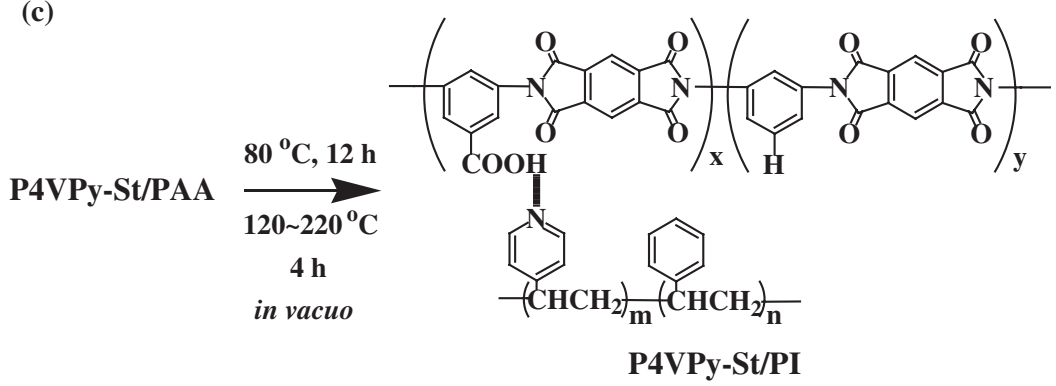

Scheme 1. Syntheses of P4VPy-St (a), PAA (b), and P4VPy-St/PI (c).

Table I. Syntheses of PAAs having various contents of carboxyl groups in a DMAc solution

\begin{tabular}{|c|c|c|c|c|c|c|}
\hline & \multicolumn{2}{|c|}{ Diamine } & \multirow{2}{*}{$\begin{array}{c}\text { Dianhydride } \\
\text { PMDA/g }\end{array}$} & \multirow{2}{*}{$\begin{array}{c}\text { Solvent } \\
\mathrm{DMAc} / \mathrm{cm}^{3}\end{array}$} & \multicolumn{2}{|c|}{ PAA } \\
\hline & $\mathrm{MPDA} / \mathrm{g}$ & $\mathrm{DABA} / \mathrm{g}$ & & & Yield/\% & $\eta_{\mathrm{sp}} / \mathrm{C}^{\mathrm{a}} / \mathrm{dm}^{3} \mathrm{~g}^{-1}$ \\
\hline PAA0 & 0.61 & 0 & 1.22 & 16.5 & 98.5 & 0.83 \\
\hline PAA50 & 0.29 & 0.41 & 1.17 & 16.9 & 94.8 & 0.81 \\
\hline PAA80 & 0.11 & 0.64 & 1.15 & 17.1 & 93.2 & 0.77 \\
\hline PAA100 & 0 & 0.69 & 0.99 & 16.5 & 75.6 & 0.75 \\
\hline
\end{tabular}

${ }^{\text {a}}$ Measured at $0.05 \mathrm{~g} / 10 \mathrm{~cm}^{3}$ in DMAc at $25^{\circ} \mathrm{C}$.

on PEG standards.

The PAAs having various contents of carboxyl groups were synthesized by the conventional polymerization of MPDA/DABA with PMDA in DMAc; the results are shown in Table I. The yield and solution viscosity decreased gradually with increasing the feed ratios of DABA to MPDA in diamine monomers. This is due to the reactivity of DABA being lower than that of MPDA.

Preparation of P4VPy-St/PAA and P4VPy-St/PI composites

Great improvements of mechanical properties would take place if good compatibilities between flexible polymers and reinforcing rigid polymers are attained by some attractive interactions, such as hydrogen bonding interactions between two polymers. Based on this expectation, the PI having carboxyl pendant groups were used as reinforcing rigid polymers for the formation of the high-performance composites used P4VPy-St(5/5) as a matrix polymer.

The in-situ polymerization of pyromellitic dianhydride (PMDA) and various molar ratios of MPDA/ DABA was carried out in DMAc solution of P4VPy$\mathrm{St}(5 / 5)$. The reaction mixture was cast on a glass plate. Resulting films were clear and transparent, suggesting 


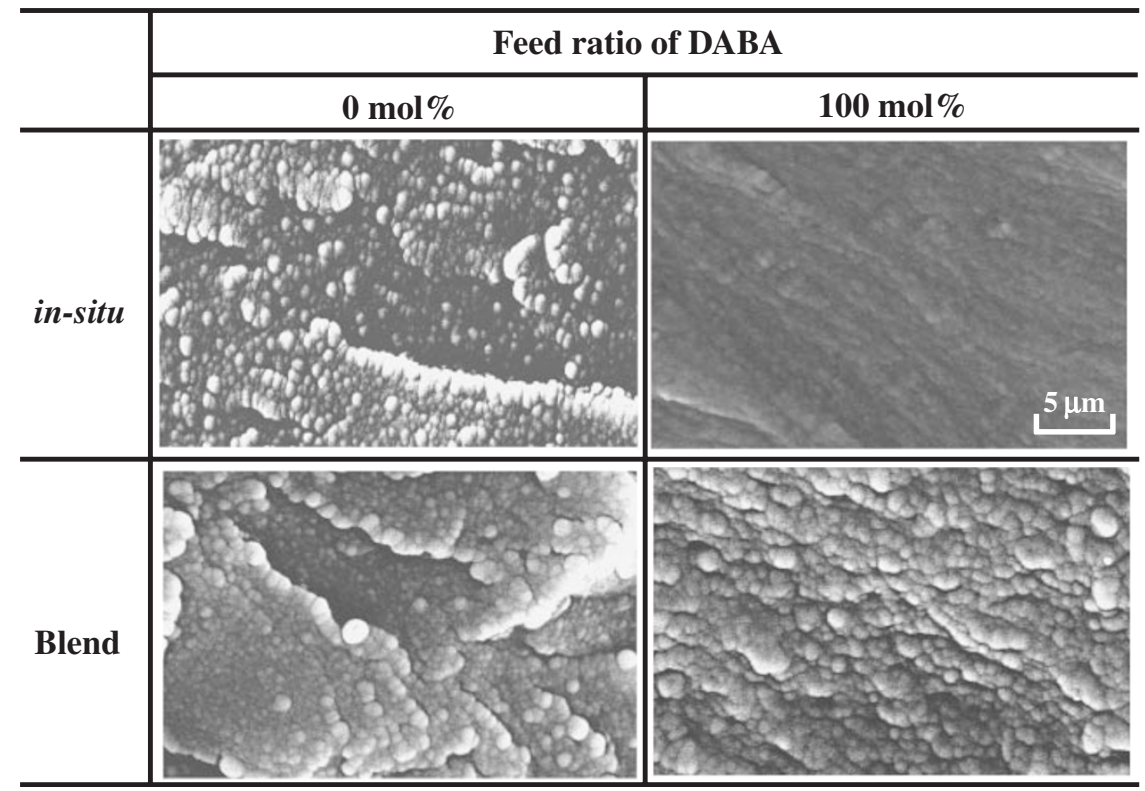

Figure 1. SEM photographs of the fractured surfaces of the P4VPy-St (5/5)/PI composite films.

good compatibilities between the copolymers and PAAs to form homogeneous blend polymers. This observation strongly suggested that compatibilities between the matrix polymer and the in-situ formed PAA were so good that an almost complete blending state could be attained to form a 'molecular composite'. The P4VPy-St/PAA films were heated stepwise to form uniform films of P4VPy-St/PI composites.

The IR spectrum for P4VPy-St(5/5)/PI composite shows the imide carbonyl bands at $1780 \mathrm{~cm}^{-1}, 1720$ $\mathrm{cm}^{-1}$, and other characteristic imide bands at 1370 $\mathrm{cm}^{-1}, 1110 \mathrm{~cm}^{-1}$, and $740 \mathrm{~cm}^{-1} ; 15$ the spectrum indicates that the imidization of P4VPy-St(5/5)/PAA composite took place completely to form P4VPy$\mathrm{St}(5 / 5) / \mathrm{PI}$ composite. It has been reported that the IR spectrum of the 2:1 (molar ratio) complex of 4-butoxybenzoic acid and 4,4'-bipyridine in the crystalline state at $100^{\circ} \mathrm{C}$ included the $\mathrm{OH}$ bands at 2500 and $1920 \mathrm{~cm}^{-1}$ that were due to strong hydrogen bonding. ${ }^{16}$

Similar spectral features were observed in the P4VPy-St(5/5)/PI composites. But these broad absorption peaks, which are due to hydrogen bonding between the pyridine moiety in the P4VPy-St copolymer and the carboxyl group in the PI, were very weak. This may be attributed to a decrease in the hydrogen bonding interaction because the aggregation of parts of the resulting PI chain having carboxyl groups occurred during the imidization processes of PAA in the P4VPy-St(5/5)/PAA on heating above $200^{\circ} \mathrm{C}$.

Figure 1 shows SEM photographs of the fractured surfaces for the composite films of P4VPy-St(5/5)/ PI $50 \mathrm{wt} \%$ derived from PAA0 or PAA100 and P4VPy-St(5/5). In the photographs of these compo-

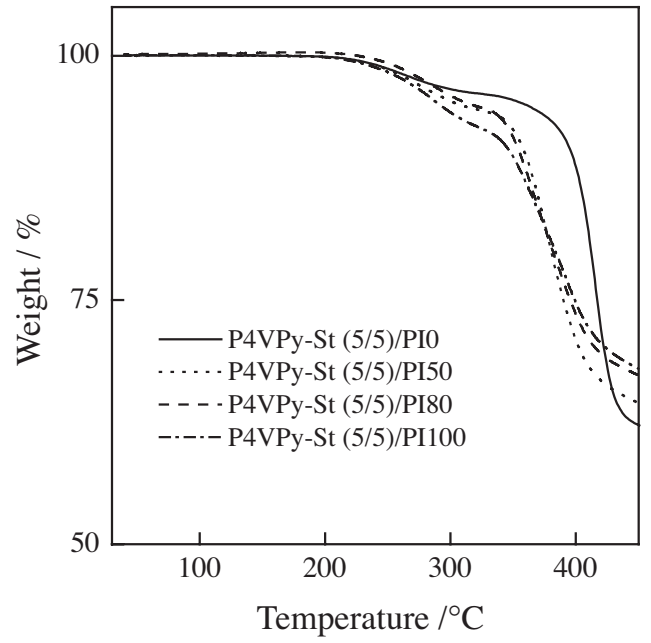

Figure 2. TG curves of the P4VPy-St (5/5)/PI composites prepared by the in-situ method.

site films, spherical particles with diameters of less than $1 \mu \mathrm{m}$ were observed. The introduction of carboxyl pendant groups into PI seems to give more compatible composites.

Thermo-gravimetric (TG) analyses of the composite films were carried out in order to detect thermal decomposition behaviors of the $\mathrm{P} 4 \mathrm{VPy}-\mathrm{St}(5 / 5) / \mathrm{PI}$ $50 \mathrm{wt} \%$ composites. TG curves of P4VPy-St $(5 / 5) /$ PI $50 \mathrm{wt} \%$ prepared by the in-situ method are shown in Figure 2. The decomposition temperatures of the composites with carboxyl pendant groups were lower than that of the composite without carboxyl pendant groups, because the decomposition temperatures of PAA were lowered as the carboxyl group content in the PAA increased. 
Table II. Mechanical properties of the P4VPy-St (5/5)/PAA or PI composites with different carboxyl group contents prepared by the in-situ and blend methods

\begin{tabular}{|c|c|c|c|c|c|}
\hline \multirow[b]{2}{*}{ Methods } & \multirow[b]{2}{*}{$\begin{array}{l}\text { Code } \\
\text { Address }\end{array}$} & \multirow{2}{*}{$\begin{array}{c}\text { Carboxyl } \\
\text { group } \\
\text { content } \\
/ \text { mol\% }\end{array}$} & \multicolumn{3}{|c|}{ Mechanical properties } \\
\hline & & & $\begin{array}{c}\text { Tensile } \\
\text { strength } \\
/ \mathrm{MPa}\end{array}$ & $\begin{array}{l}\text { Tensile } \\
\text { modulus } \\
/ \mathrm{GPa}\end{array}$ & $\begin{array}{c}\text { Ultimate } \\
\text { elongation } \\
/ \%\end{array}$ \\
\hline \multirow{8}{*}{ Blend } & PAA0 & 0 & 15.1 & 0.48 & 11.4 \\
\hline & PAA50 & 50 & 23.7 & 1.00 & 26.4 \\
\hline & PAA80 & 80 & 27.7 & 1.14 & 40.0 \\
\hline & PAA100 & 100 & 34.2 & 1.37 & 44.3 \\
\hline & PI0 & 0 & 17.3 & 0.58 & 10.3 \\
\hline & PI50 & 50 & 31.2 & 1.17 & 14.5 \\
\hline & PI80 & 80 & 47.1 & 1.81 & 16.8 \\
\hline & PI100 & 100 & 50.2 & 2.06 & 28.5 \\
\hline \multirow{8}{*}{ in-situ } & PAA0 & 0 & 22.3 & 0.63 & 17.7 \\
\hline & PAA50 & 50 & 33.9 & 1.00 & 24.5 \\
\hline & PAA80 & 80 & 39.7 & 1.23 & 36.5 \\
\hline & PAA100 & 100 & 44.9 & 1.74 & 40.8 \\
\hline & PI0 & 0 & 48.9 & 1.41 & 13.5 \\
\hline & PI50 & 50 & 53.8 & 1.88 & 15.5 \\
\hline & PI80 & 80 & 60.3 & 2.27 & 17.6 \\
\hline & PI100 & 100 & 70.1 & 2.43 & 22.1 \\
\hline
\end{tabular}

\section{Mechanical Properties of Composite Films}

Results of the tensile tests of the P4VPy-St(5/5)/ PAA or PI composite films with different carboxyl group contents prepared by in-situ method and blend method are summarized in Table II.

The tensile strength, tensile modulus and ultimate elongation of the P4VPy-St(5/5)/PAA or PI composite films increased with increasing feed ratios of DABA/MPDA in diamine monomers.

The tensile strengths of P4VPy-St $(5 / 5) / \mathrm{PAA}$ and $\mathrm{P} 4 \mathrm{VPy}-\mathrm{St}(5 / 5) / \mathrm{PI}$ composite films are plotted as a function of feed ratio of DABA/MPDA in diamine monomers, in Figures 3 and 4, respectively. Particularly, the tensile strengths of the P4VPy-St(5/5)/ $\mathrm{PAA}$ and $\mathrm{P} 4 \mathrm{VPy}-\mathrm{St}(5 / 5) / \mathrm{PI}$ composite films increased with increasing feed ratios of DABA/MPDA in diamine monomers, as shown in these figures. In addition, the tensile strengths of the composite films prepared by the in-situ method were higher than those of the films prepared by the blend method.

The P4VPy-St(5/5)/PI composite film was found to have a high tensile strength, compared with P4VPy-St(5/5)/PAA composite film. This indicates that the PI structure formed by stepwise heat-treatment of the PAA in the composites greatly enhanced the tensile strength.

Figure 5 shows PAA and PI content dependencies of tensile strength for $\mathrm{P} 4 \mathrm{VPy}-\mathrm{St}(5 / 5) / \mathrm{PAA}$ and P4VPy-St(5/5)/PI composite films. The tensile strength of these composite films was higher than that of either of the individual polymer components, as

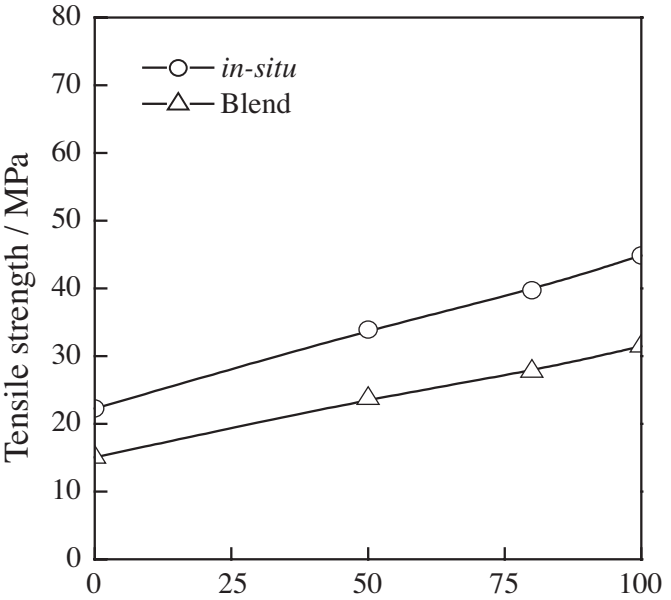

Feed ratio of DABA in diamines $/ \mathrm{mol} \%$

Figure 3. Tensile strength of the P4VPy-St (5/5)/PAA composite films prepared by the in-situ method $(O)$ and the blend method $(\triangle)$ as a function of the feed ratio of DABA/MPDA.

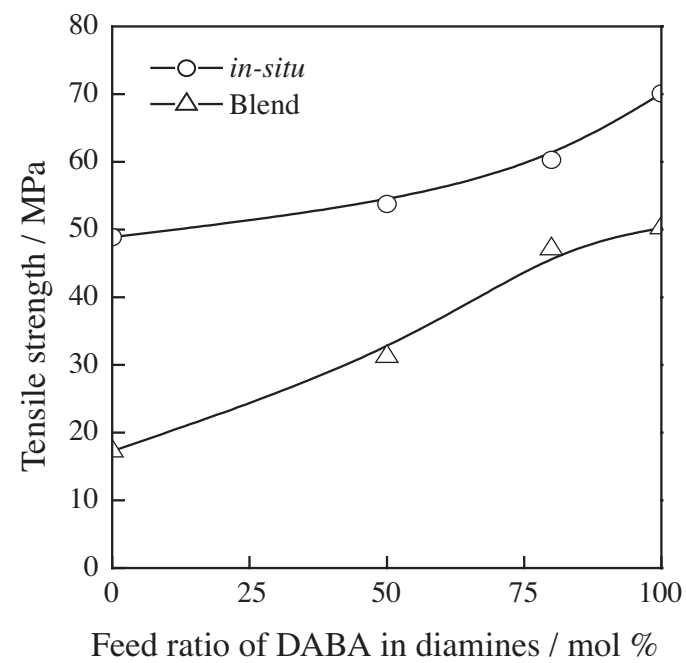

Figure 4. Tensile strength of the P4VPy-St (5/5)/PI composite films prepared by the in-situ method $(\bigcirc)$ and the blend method $(\triangle)$ as a function of the feed ratio of DABA/MPDA.

shown in the figure. The reinforcing effect of PI having carboxyl pendant groups may be attributed to the good compatibility, based on the hydrogen bonding interaction, between the pyridine moiety in the matrix copolymer and the carboxyl pendant group introduced into the resulting PI. Presumably, this hydrogen bonding interaction and the in-situ polymerization method made the two polymers compatible.

\section{CONCLUSIONS}

High-performance composites of poly(4-vinylpyridine-co-styrene) copolymer (P4VPy-St) and polyimides (PI) having carboxyl pendant groups were suc- 


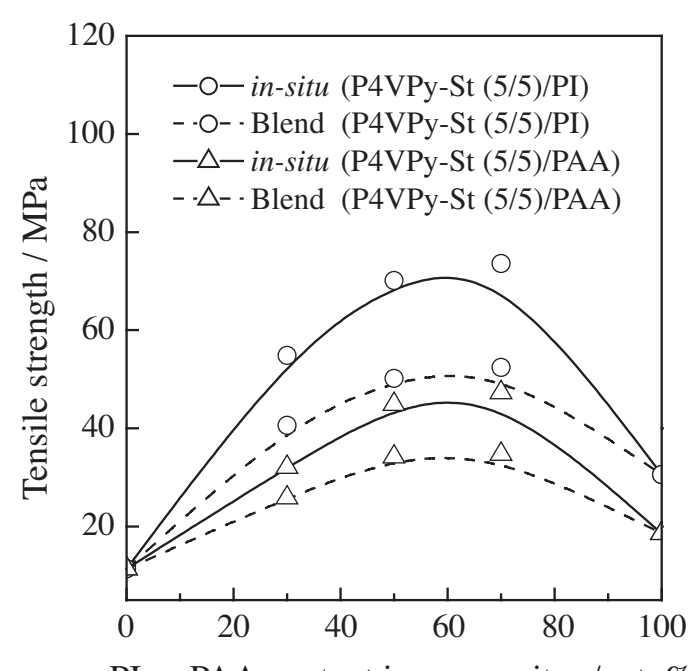

PI or PAA content in composites / wt. \%

Figure 5. PAA or PI content dependence of tensile strength of P4VPy-St $(5 / 5) / \mathrm{PAA}(\triangle)$ and P4VPy-St $(5 / 5) / \mathrm{PI}(\bigcirc)$ composite films prepared by the in-situ method (-) and the blend method $(--)$.

cessfully prepared by the so-called 'in-situ polymerization method' and their mechanical properties were investigated. The tensile strength of the resulting composite films increased with increasing carboxyl group content in PI. The hydrogen bonding interaction between the pyridine moiety in the P4VPy-St copolymer and the carboxyl group introduced into PI greatly enhanced both the compatibilities and the tensile strengths of the composite films. Furthermore, the tensile strengths of the composite films prepared by the in-situ method were much higher than those of the films prepared by the blend method. The introduction of an attractive interaction between matrix polymers and reinforcing polymers and the in-situ polymerization method are thus very useful for the preparation of high-performance polymer composites.

Acknowledgment. This work was supported by a Grant-in-Aid for Scientific Research (No. 13450383) from the Ministry of Education, Culture, Sports, Sci- ence and Technology, Japan. We acknowledge the useful discussions with Prof. Masa-aki Kakimoto, Tokyo Institute of Technology, Tokyo, Japan.

\section{REFERENCES}

1. W.-F. Hwang, D. R. Wiff, C. L. Benner, and T. E. Helminak, J. Macromol. Sci. Phys., B, 22, 231 (1983).

2. M. Takayanagi, T. Ogata, M. Morikawa, and T. Kai, J. Macromol. Sci., Part B: Phys., 17, 518 (1980).

3. M. Takayanagi and T. Katayose, J. Polym. Sci., Polym. Chem. Ed., 19, 1133 (1980).

4. N. Ogata, K. Sanui, and H. Itaya, Polym. J., 22, 85 (1990).

5. E. Debeaupte, M. Watanabe, K. Sanui, and N. Ogata, Chem. Mater., 4, 1123 (1992).

6. K. Sanui, N. Ogata, K. Kamitani, and M. Watanabe, J. Polym. Sci., Part A: Polym. Chem., 31, 597 (1993).

7. J. Ann, M. Rikukawa, K. Sanui, and N. Ogata, Polym. J., 28, 496 (1996).

8. Y. Ayaki, M. Rikukawa, M. Watanabe, K. Sanui, and N. Ogata, Polym. J., 26, 325 (1994).

9. M. Vivas de Meftahi and J. M. J. Fréchet, Polymer, 29, 477 (1988)

10. A. Sato, T. Kato, and T. Uryu, J. Polym. Sci., Part A: Polym. Chem., 34, 503(1996).

11. a) T. Kato and J. M. J. Fréchet, Macromolecules, 22, 3818 (1989).

b) T. Kato, H. Kihara, U. Kumar, T. Uryu, and J. M. J. Fréchet, Angew. Chem., Int. Ed., 33, 1644 (1994).

12. K. Sanui, Y. Kiyohara, M. Rikukawa, and N. Ogata, React. Funct. Polym., 30, 293 (1996).

13. a) Y. Imashiro, H. Yokoi, M. Yoshikawa, K. Sanui, and N. Ogata, Nippon Kagaku Kaishi, 875 (1983).

b) N. Ogata, K. Sanui, H. Tanaka, H. Fujimura, and Y. Kawachi, Kobunshi Ronbunshu, 38, 583 (1981).

14. N. Ogata, K. Sanui, H. Tanaka, H. Matsuo, and F. Iwaki, J. Polym. Sci., Polym. Chem. Ed., 19, 2609 (1981).

15. R. Yokota, S. Yamamoto, S. Yano, T. Sawaguchi, M. Hasegawa, H. Yamaguchi, H. Ozawa, and R. Sato, Polyimides Other High Temp. Polym., 1, 101 (2001).

16. T. Kato, J. M. J. Fréchet, P. G. Wilson, T. Saito, T. Uryu, A. Fujishima, C. Jin, and F. Kaneuchi, Chem. Mater., 5, 1094 (1993). 